\title{
PENENTUAN KEMIRINGAN SUDUT OPTIMAL PANEL SURYA
}

\author{
T.M. Azis Pandria ${ }^{* 1}$, Mukhlizar ${ }^{2}$ \\ ${ }^{1,2}$ Program Studi Teknik Industri, Fakultas Teknik, Universitas Teuku Umar \\ E-mail: ${ }^{1}$ azispdr@gmail.com, ${ }^{2}$ mukhlizar@utu.ac.id
}

\begin{abstract}
This paper discusses the determination of the optimal tilt angle of solar panels in the Nagan Raya aims to maximize acceptance of solar radiation. Adjust the titl angle customized panels with latitude location can maximize the acceptance of solar radiation. Calculation of the optimal angle variations is simulated at an angle of $10^{\circ}-50^{\circ}$ intervals between angle $10^{\circ}$. For the purposes of simulation calculation of optimal tilt angle against the value-based maximum radiation on tilted surface, use data that NASA SEE. A study conducted in Nagan Raya this is determined based on the google maps coordinates of the point. This research resulted in recommendations for the optimum tilt angle in Nagan Raya who was the tilt $40^{\circ}$ with South-facing orientation. The results of the technical study of this research can be used as initial references against the installation of a solar panel fixed type in the Nagan Raya.
\end{abstract}

Keywords: Optimum angle, Solar panels, NASA SSE, Nagan Raya, Renewable Energy

\section{PENDAHULUAN}

Energi matahari merupakan sumber energi abstrak yang tak terbatas, dan merupakan salah satu sumber energi terbarukan. Pemanfaatan energi dari sumber energi terbarukan (EBT) meningkat tajam di seluruh dunia, termasuk Indonesia. Nagan Raya merupakan salah satu wilayah di Indonesia yang memiliki potensi energi matahari yang cukup besar $\left(5.02 \mathrm{kWh} / \mathrm{m}^{2}\right)$ rata - rata per tahun. Pemanfaatan energi matahari sebagai pembangkit energi listrik sangat tepat untuk diterapkan di Nagan Raya, mengingat letak geografis Nagan raya yang dekat dengan garis equator [1]. Pemanfaatan energi matahari menjadi energi listrik menggunakan perangkat phoyovoltaic panel (panel surya). Oleh karena itu diperlukan kajian teknis terhadap penentuan sudut optimum panel surya, untuk memaksimalkan penerimaan energi matahari oleh panel surya [2].

Salah satu cara memaksimalkan penerimaan radiasi matahari oleh panel surya adalah dengan memposisikan panel pada posisi kemiringan optimal. Tujuan memiringkan panel pada posisi optimal, agar permukaan panel selalu berada tepat menghadap matahari sepanjang tahun. latitude lokasi berpengaruh terhadap radiasi yang diterima permukaan panel, sehingga posisi optimum suatu lokasi dengan lokasi lainnya dapat berbeda. Kajian teknis terhadap sudut kemiringan optimum diberbagai tempat di seluruh dunia telah banyak dilakukan, seperti Tarek O.Kaddoura et al. [3] melakukan penentuan terhadap sudut kemiringan optimum di berbagai kota di Kerajaan Arab Saudi, menggunakan perhitungan teoritis. Data radiasi pada permukaan horizontal dari NASA digunakan untuk memprediksi sudut kemiringan optimum, menggunakan program Matlab. kode Matlab dibangun untuk mensimulasikan variasi sudut miring. Hasil penelitian menunjukkan, dengan 
menyesuaikan sudut kemiringan optimum per bulan dan per musim dapat meningkatkan penerimaan energi sekitar $7,74 \%$ dan $6,38 \%$, dibandingkan dengan sudut miring tetap. Penyesuaian sudut miring diusulkan secara berkala dapat meningkatkan penerimaan energi matahari $7.35 \%$ dibandingkan dengan penyesuaian bulanan. Rudi Darussalam et al. [4] melakukan optimalisasi sudut azimut dan sudut kemiringan panel surya di Kabupaten Bandung, yang bertujuan untuk memaksimalkan penyerapan radiasi matahari oleh panel surya. Kajian ini merupakan tinjauan teoritis penentuan sudut optimal berdasarkan latitude lokasi. Hasil penelitian menunjukkan variasi sudut optimal yang terjadi di wilayah Ciparay, Kabupaten Bandung. Handoyo et al. [5] melakukan penentuan sudut kemiringan optimal solar collector berdasarkan radiasi global dan tersebar bulanan. Estimasi penerimaan radiasi berdasarkan nilai radiasi langsung maksimal pada permukaan kolektor yang terpasang di Surabaya pada lokasi latitude $4.2^{\circ}$ dari arah utara. Hasil penelitian menunjukkan, untuk collector yang terpasang di surabaya, sudut optimal antara tanggal 12 Maret -30 September bervariasi antara $0^{\circ}-40^{\circ}$ (orientasi ke utara) dan selama tanggal 1 Oktober - 11 Maret antara $0^{\circ}-30^{\circ}$ (orientasi ke selatan). Pilihan lain adalah dengan memasang dua buah collector secara bersamaan, dengan kondisi satu menghadap timur untuk pagi hari, dan satu lagi menghadap barat untuk sore hari. Pada orientasi tersebut, sudut optimal adalah $36^{\circ}-39.4^{\circ}$. Kadir Bakirci [6] melakukan penentuan sudut kemiringan optimal panel surya, untuk memaksimalkan penerimaan energi menggunakan data radiasi yang diukur di delapan provinsi besar di Turki. Hasil menunjukkan, sudut kemiringan optimum permukaan bervariasi dari $0^{\circ}-90^{\circ}$. Sudut optimum ditentukan dengan mencari nilai maksimum total per hari selama periode tertentu. Sudut kemiringan optimum berubah antara $0^{\circ}-65^{\circ}$ sepanjang tahun di Turki. Sudut optimum terendah terjadai pada Juni dan Juli yang berada pada $0^{\circ}$.

Makalah ini melakukan penentuan sudut kemiringan optimal panel surya di kabupaten Nagan Raya (3.4 $\left.{ }^{\circ} \mathrm{LU}-96.11^{\circ} \mathrm{BT}\right)$, berdasarkan nilai radiasi total pada permukaan bidang miring. Penyesuaian sudut optimal bertujuan untuk memaksimalkan penerimaan radiasi matahari oleh panel surya.

\section{METODE PENELITIAN}

Memposisikan panel surya pada sudut kemiringan optimal, dapat meningkatkan efesiensi hingga pada tingkat maksimal. Semakin tinggi nilai efesiensi sebuah panel, maka akan semakin baik performa dari panel tersebut [2]. Posisi sudut kemiringan yang berada tidak pada posisi optimal berpotensi kehilangan nilai radiasi maksimal. Sudut kemiringan optimal ditentukan berdasarkan nilai radiasi yang mengenai permukaan bidang miring. Penelitian ini menggunakan metode faktor geografis, untuk menentukan nilai rasio radiasi langsung pada permukaan miring $(R b)$. Nilai rasio merupakan salah satu faktor dari komponen radiasi total pada permukaan bidang miring [7].

\subsection{Radiasi Matahari pada Sudut Permukaan Miring}

Radiasi matahari yang mengenai permukaan bidang miring terdiri dari tiga komponen, diantaranya radiasi langsung $\left(H_{B}\right)$, radiasi tersebar $\left(H_{D}\right)$ dan radiasi pantulan $\left(H_{R}\right)$. Secara matematis ketiga komponen radiasi tersebut diberikan pada persamaan (1) [3].

$$
H_{T}=\left(H_{g}-H_{d}\right) R_{b}+H_{g}\left(\frac{1-\cos \beta}{2}\right)+H_{d}\left(\frac{1-\cos \beta}{2}\right)
$$

dimana $\mathrm{Hg}$ dan $\mathrm{Hd}$ merupakan radiasi langsung dan tersebar pada permukaan horizontal, dan $R_{b}$ merupakan rasio radiasi langsung terhadap permukaan miring. Semua nilai tersebut 
dipengaruhi oleh latitude lokasi. Untuk lokasi yang berada di sisi utara bumi, maka permukaan panel surya harus dihadapkan tepat ke selatan untuk mendapatkan orientasi optimum. Nilai $R_{b}$ untuk lokasi utara bumi diberikan pada persamaan (2) [7].

$$
R_{b}=\frac{\cos \theta}{\cos \theta_{z}}
$$

$\operatorname{Cos} \theta$ merupakan sudut datang radiasi matahari yang ditentukan dengan persamaan (3) seperti diberikan dibawah ini [7].

$$
\begin{aligned}
\cos \theta= & \sin \delta \sin \phi \cos \beta-\sin \delta \sin \phi \sin \beta+\cos \delta \cos \phi \cos \beta \cos \omega \\
& +\cos \delta \sin \beta \sin \gamma \sin \omega+\cos \delta \sin \phi \sin \beta \cos \gamma \cos \omega
\end{aligned}
$$

dan untuk nilai $\cos \theta \mathrm{z}$ merupakan nilai azimut matahari yang dihitung dengan persamaan (4) seperti diberikan sebagai berikut.

$$
\cos \theta_{z}=\cos \phi \cos \delta \cos \omega+\sin \phi \sin \delta
$$

dimana $\phi$ merupakan latitude lokasi, $\beta$ merupakan sudut miring permukaan panel surya, $\gamma$ merupakan azimut permukaan, $0^{\circ}$ menghadap selatan dan $180^{\circ}$ menghadap utara. Notasi $\omega$ merupakan sudut jam, $\delta$ merupakan sudut deklinasi matahari yang dapat ditentukan dengan persamaan (5) [7].

$$
\delta=23.45 \sin \left(\frac{360}{365}(284+n)\right.
$$

dimana notasi $n$ merupakan nomor untuk hari pertama setiap bulan, yang diberikan pada Tabel 1.

\begin{tabular}{cccc} 
Tabel 1 Nomor Hari Pertama Setiap Bulan \\
\hline Bulan & Nomor & Bulan & Nomor \\
\hline Jan & $n=1$ & Jul & $n=182$ \\
Feb & $n=32$ & Agt & $n=213$ \\
Mar & $n=60$ & Sep & $n=244$ \\
Apr & $n=91$ & Okt & $n=274$ \\
Mei & $n=121$ & Nov & $n=305$ \\
Jun & $n=152$ & Des & $n=335$ \\
\hline
\end{tabular}

Hubungan skematik antar sudut terhadap permukaan miring, baik pada permukaan solar collector maupun panel surya tampak pada Gambar 1.

\subsection{Radiasi Langsung}

Komponen radiasi langsung pada permukaan miring $\left(H_{B}\right)$ dihitung berdasarkan nilai radiasi langsung pada permukaan horizontal $\left(H_{b}\right)$, hubungan tersebut secara matematis diberikan pada persamaan (6) [6].

$$
H_{B}=\left(H_{g}-H_{d}\right) R_{b}
$$




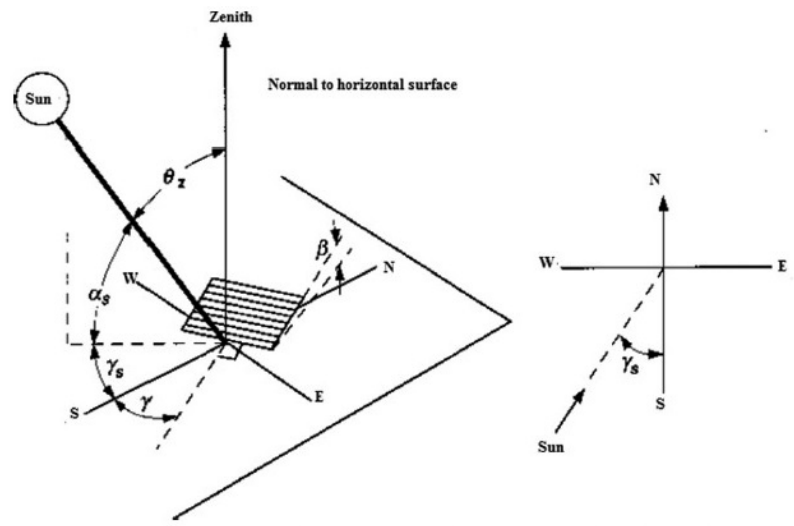

Gambar 1 Hubungan Skematik Antar Sudut Terhadap Permukaan Miring [8].

dimana $H_{g}$ dan $H_{d}$ merupakan radiasi global dan radiasi tersebar pada permukaan horizontal di suatu lokasi, dan $R b$ merupakan rasio radiasi langsung pada permukaan.

\subsection{Radiasi Tersebar}

Radiasi tersebar pada permukaan bidang miring $\left(H_{D}\right)$, dihitung menggunakan nilai radiasi tersebar pada permukaan horizontal $\left(H_{d}\right)$. Secara matematis hubungan terhadap radiasi tersebar diberikan pada persamaan (7) [9].

$$
H_{D}=R_{d} H_{d}
$$

Salah satu unsur yang diperhitungkan pada persamaan tersebut adalah rasio radiasi tersebar $\left(R_{d}\right)$ pada permukaan miring, disamping radiasi pada permukaan horizontal. Prediksi terhadap nilai rasio radiasi tersebar secara umum terbagi atas dua model, pertama model isotropic dan kedua model anisotropic. Model isotropic mengasumsikan intesitas radiasi bernilai sama di seluruh penjuru kubah langit, sehingga radiasi tersebar pada permukaan miring tergantung kilasan cahaya yang terlihat di kubah langit [8]. Model anisotropic mengasumsikan radiasi tersebar yang mengelilingi matahari (dekat piringan matahari) dijumlahkan dengan komponen radiasi tersebar dari sisi kubah langit. Terdapat beberapa model isotropic yang diusulkan, diantaranya :

Model Badescu [8].

$$
R_{d}=\frac{3+\cos (2 \beta)}{4}
$$

Model Tien et al. [8]

$$
R_{d}=1-\frac{\beta}{180}
$$

Model Liu and Jordan [8]

$$
R_{d}=\frac{1+\cos \beta}{2}
$$

Sedangkan untuk model anisotropic seperti yang di usulkan oleh Reindel et al. diberikan pada persamaan berikut. 


$$
R_{d}=\frac{H_{b}}{H_{0}} R_{b}+\left(1-\frac{H_{b}}{H_{0}}\right)\left(\frac{1+\cos \beta}{2}\right)\left(1+\sqrt{\frac{H_{b}}{H_{g}} \sin ^{3} \frac{\beta}{2}}\right)
$$

Nilai rasio radiasi tersebar yang digunakan pada penelitian menggunakan ini model yang diusulkan oleh Liu and Jordan.

\subsection{Radiasi Pantulan}

Nilai radiasi pantulan dapat diprediksi menggunakan persamaan (12), dimana pada persamaan ini komponen ground albedo turut dihitung [3].

$$
H_{R}=H_{g} \rho \frac{1-\cos \beta}{2}
$$

Ground albedo atau nilai pantulan permukaan merupakan nilai spesifik dimana panel surya dipasang. Bila jenis permukaan tidak diketahui, maka nilai ground albedo dapat diasumsikan sebesar 0,2 [6]. Nilai ground albedo berdasarkan permukaan tanah seperti diberikan Tabel 2.

Tabel 2. Nilai Albedo Permukaan [7].

\begin{tabular}{cccc}
\hline Material & Albedo (ALB) & Material & Albedo (ALB) \\
\hline Garss (July, Aug) & 0.25 & Aspalt & 0.15 \\
Lawn & $0.18 \ldots 0.23$ & Concrete, clean & 0.30 \\
Unnown fieds & 0.26 & Concrate, weathered & 0.20 \\
Wood & $0.05 \ldots 0.18$ & Snow cover, new & $0.80 \ldots 0.90$ \\
Heat surfaces & $0.10 \ldots 0.25$ & Snow cover, old & $0.45 \ldots 0.70$ \\
\hline
\end{tabular}

Interaksi semua jenis radiasi terhadap bumi baik pada posisi luar atmosfir, maupun dalam atmosfir tampak pada Gambar 2.

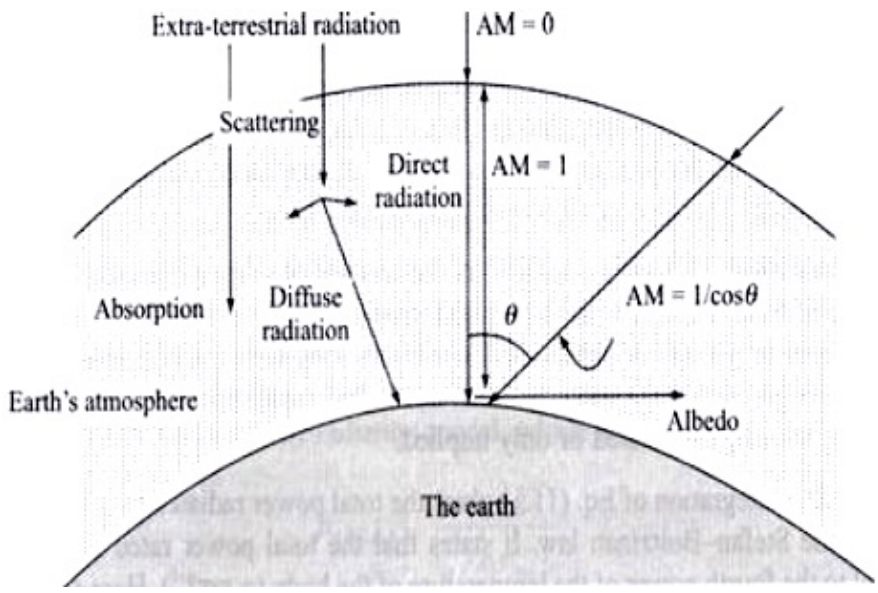

Gambar 2 Interaksi Radiasi Terhadap Bumi [4]. 
Berdasarkan simulasi sofware Pvsyst V5.52, data radiasi variasi radiasi dan solar path di wilayah Nagan Raya menggunakan data NASA SSE ditampilkan pada Tabel 3.

\subsection{Simulasi dan Optimalisasi}

Coding Matlab digunakan untuk membangun simulasi guna mendapatkan nilai sudut kemiringan optimum per bulan yang ditentukan pada waktu maksimum radiasi matahari yang dihitung menggunakan persamaan (13).

$$
H_{T}=H_{B}+H_{B}+H_{R}
$$

Tabel 3 Radiasi Global Nagan raya

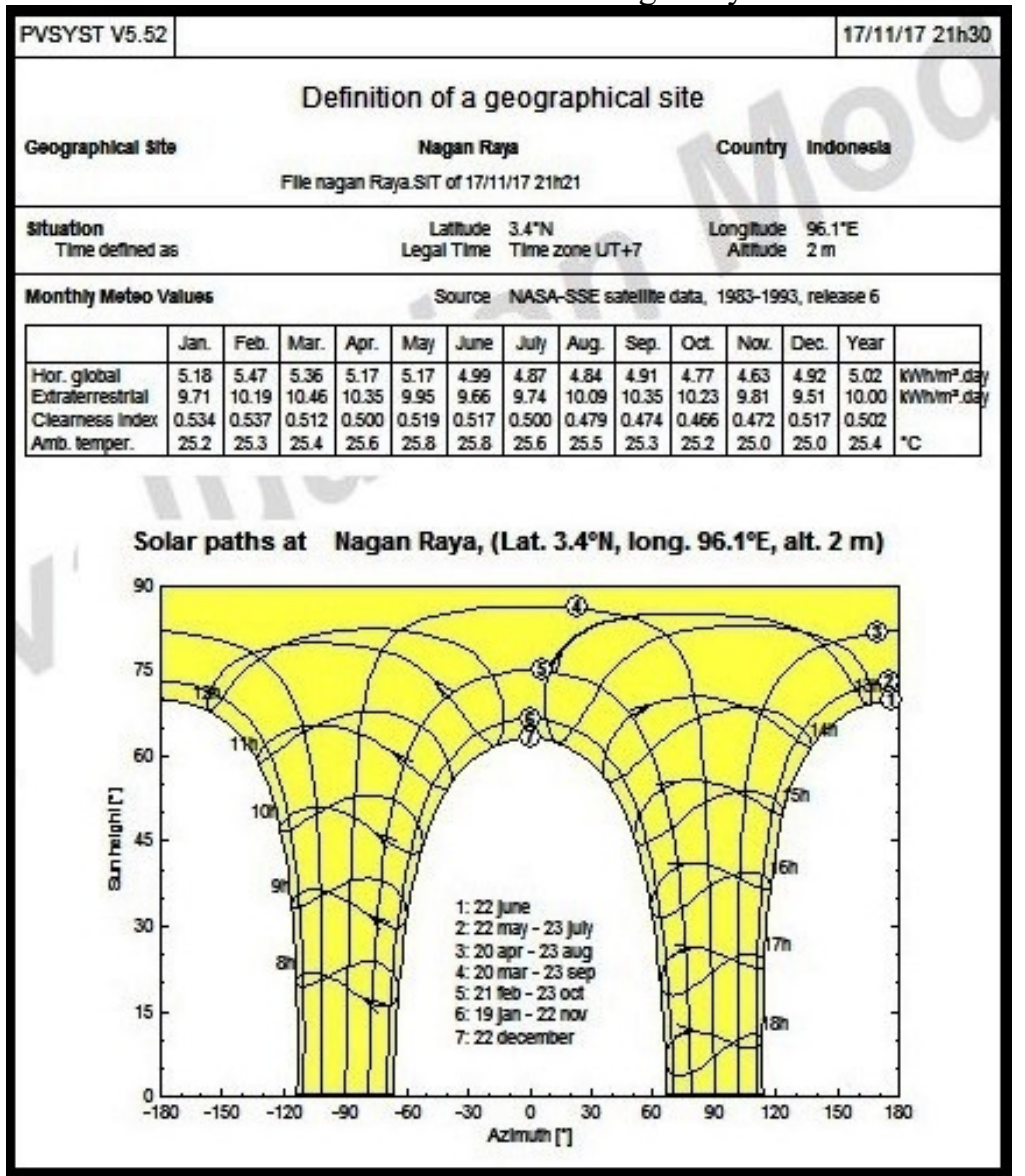

dimana $H_{T}$ adalah radiasi total pada permukaan bidang miring, $H_{B}$ adalah total radiasi langsung pada permukaan miring, $H_{D}$ merupakan total radiasi tersebar pada permukaan miring, dan $H_{R}$ merupakan radiasi pantulan dari permukaan bumi terhadap permukaan panel [3]. Artikel ini menggunakan data radiasi pada permukaan horizontal yang sediakan website NASA. data radiasi langsung dan tersebar merupakan data rata - rata selama 22 tahun di banyak lokasi. Data yang telah diperoleh kemudian dirubah kedalam bentuk coding Matlab untuk dibangun dan disimulasikan variasi sudut kemiringan panel surya. Coding Matlab mencari variasi nilai terhadap sudut miring menggunakan persamaan (1) mulai dari sudut $10^{\circ}-90^{\circ}$ dengan interval $10^{\circ}$. Radiasi yang dihasilkan digunakan untuk mengambarkan urutan variasi radiasi matahari menurut sudut kemiringan per bulan selama setahun. 


\section{HASIL DAN PEMBAHASAN}

Gambar 3 menampilkan sudut kemiringan optimal panel surya di Nagan Raya selama setahun, dengan orientasi panel menghadap selatan (equator). Orientasi tepat menghadap utara merupakan orientasi optimum dengan asumsi arah tidak terjadi penyimpangan arah orientasi (sudut azimut). Variasi sudut optimal dihasilkan yaitu bulan Januari $40^{\circ}$, Februari $20^{\circ}$, Maret $10^{\circ}$, April $40^{\circ}$, Mei $40^{\circ}$, Juni $40^{\circ}$, Juli $10^{\circ}$ Agustus $40^{\circ}$, September $40^{\circ}$, Oktober $20^{\circ}$, November $20^{\circ}$, Desember $40^{\circ}$.



Gambar 3 Sudut Kemiringan Optimum Orientasi Menghadap Selatan

Grafik yang tampak pada gambar menampilkan perbedaan yang cukup jauh antar sudut, dan pengulangan sudut yang paling banyak berada di sudut $40^{\circ}$. Untuk sudut lainnya hanya terjadi dua kali pengulangan saja, seperti pada bulan Maret dan Juli $10^{\circ}$, dan Februari, Oktober - November sudut $20^{\circ}$. Kondisi tersebut terjadi karena lokasi tempat panel surya dipasang berada disebelah utara equator, sehingga saat permukaan panel surya dihadapkan ke selatan ketinggian matahari berada di posisi puncak dan kemiringan panel terhadap matahari paling optimal berada diatas sudut $30^{\circ}$.

Gambar 4 menampilkan sudut optimum panel surya dengan orientasi panel menghadap selatan. Tampak pada gambar, nilai radiasi yang dihasilkan di beberapa sudut bernilai negatif. Kondisi ini terhadi karena saat panel dihadapkan ke utara, matahari berada dibelakan panel surya. Saat matahari berada di belakang panel surya, radiasi yang diterima panel berada pada nilai negatif. Naum kondisi tersebut sebenar juga merupakan sudut optimal juga. 


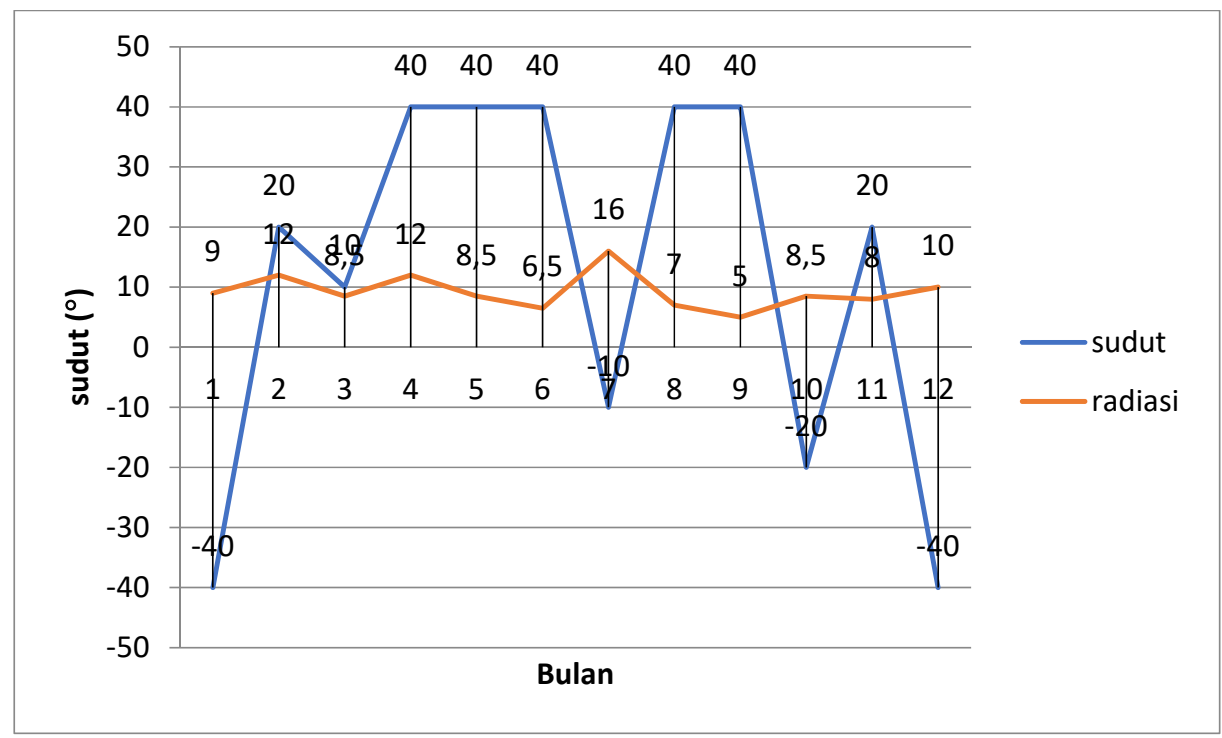

Gambar 4 Sudut Kemiringan Optimum Orientasi Menghadap Utara

Memposisikan sudut kemiringan panel surya berdasarkan periode tertentu sepeti per bulan atau per musim dapat meningkatkan penerimaan radiasi maksimal sepanjang tahun. Kondisi tersebut dapat dilihat pada Gambar 3 dan 4, dimana penyesuaian sudut per bulan dapat meningkatkan penerimaan radiasi matahari tahunan. Sudut kemirngan $40^{\circ}$ dapat dijadikan patokan penyesuaian per bulan, karena sudut ini paling banyka terjadi pengulangannya selama satu tahun.

\section{KESIMPULAN}

Sudut kemiringan optimal di Nagan Raya berdasarkan hasil perhitungan simulasi dan analisa dapat disimpulkan bahwa penyesuaian sudut miring permukaan panel surya dari Januari - Desember dengan orientasi menghadap selatan pada variasi sudut $10^{\circ}-50^{\circ}$ dapat meningkatakan penerimaan radiasi matahari oleh panel surya. Sudut optimal yang direkomendasikan diwilayah Nagan Raya berada pada sudut $40^{\circ}$.

\section{SARAN}

Disarankan untuk dilakukan pengukuran langsung terhadap nilai radiasi matahari di wilayah Nagan Raya dan sekitarnya, karena perbedaan nilai radiasi mungkin saja terjadi. Bila terjadi perbedaan nilai radiasi global antara data NASA dengan pengukuran langsung, maka sudut optimal per bulan dapat saja berubah.

\section{DAFTAR PUSTAKA}

[1] “https://eosweb.larc.nasa.gov/cgi-bin/sse.”, diakses tanggal 02/08/2017.

[2] A. K. Yadav and S. S. Chandel, "Tilt angle optimization to maximize incident solar 
radiation : A review," Renew. Sustain. Energy Rev., vol. 23, pp. 503-513, 2013.

[3] T. O. Kaddoura, M. A. M. Ramli, and Y. A. Al-turki, "On the estimation of the optimum tilt angle of PV panel in Saudi Arabia," Renew. Sustain. Energy Rev., vol. 65, pp. 626-634, 2016.

[4] R. Darussalam, A. Rajani, and T. D. Atmaja, "PENGATURAN ARAH AZIMUTH DAN SUDUT TILT PANEL PHOTOVOLTAIC UNTUK OPTIMALISASI RADIASI MATAHARI,” vol. V, pp. 31-36, 2016.

[5] E. A. Handoyo and D. Ichsani, "The optimal tilt angle of a solar collector," Phys. Procedia, vol. 32, pp. 166-175, 2013.

[6] K. Bakirci, "General models for optimum tilt angles of solar panels: Turkey case study," Renewable and Sustainable Energy Reviews, vol. 16, no. 8. Elsevier, pp. 6149-6159, 2012.

[7] J. A. Duffie and W. A. Beckman, "Solar Engineering of Thermal Processes Solar Engineering," 2013, p. 936.

[8] D. Yang, "Solar radiation on inclined surfaces : Corrections and benchmarks," Sol. Energy, vol. 136, pp. 288-302, 2016.

[9] K. Mertens, Photovoltaics," (Fundamental, Technology and Practice), John Wiley \& Sons Ltd, 2014. 